\section{Deficiency of the Iron-Sulfur Clusters of Mitochondrial Reduced Nicotinamide-Adenine Dinucleotide-Ubiquinone Oxidoreductase (Complex I) in an Infant with Congenital Lactic Acidosis}

Randall W. Moreadith, Mark L Batshaw, Tomoko Ohnishi, Douglas Kerr, Barry Knox, Daniel Jackson, Ralph Hruban, Jean Olson, Baltazar Reynafarje, and Albert L. Lehninger Departments of Physiological Chemistry, Pediatrics, and the John F. Kennedy Institute, The Johns Hopkins Medical Institutions, Baltimore, Maryland 21205; The Johnson Research Foundation, The University of Pennsylvania, Philadelphia, Pennsylvania 19104; Department of Pediatrics, Case Western Reserve University, Cleveland, Ohio 44106
A serum lactat nine, who had a moderate to profound decrease in the ability of mitochondria from four organs to oxidize pyruvate, malate plus glutamate, citrate, and other $\mathrm{NAD}^{+}$-linked respiratory substrates. The capacity to oxidize the flavin adenine dinucleotide-linked substrate, succinate, was normal. The most pronounced deficiency was in skeletal muscle, the least in kidney mitochondria. Enzymatic assays on isolated mitochondria ruled out defects in complexes II, III, and IV of the respiratory chain. Further studies showed that the defect was localized in the inner membrane mitochondrial NADHubiquinone oxidoreductase (complex I). When ferricyanide was used as an artificial electron acceptor, complex I activity was normal, indicating that electrons from NADH could reduce the flavin mononucleotide cofactor. However, electron paramagnetic resonance spectroscopy performed on liver submitochondrial particles showed an almost total loss of the iron-sulfur clusters characteristic of complex I, whereas normal signals were noted

Dr. Moreadith is the recipient of a National Research Service Award from the U. S. Public Health Service. His current address is the Duke University Medical Center, Durham, North Carolina.

Received for publication 6 February 1984 and in revised form 18 April 1984.

J. Clin. Invest.

(c) The American Society for Clinical Investigation, Inc.

0021-9738/84/09/0685/13 $\$ 1.00$

Volume 74, September 1984, 685-697 for other mitochondrial iron-sulfur clusters. This infant is presented as the first reported case of congenital lactic acidosis caused by a deficiency of the iron-sulfur clusters of complex I of the mitochondrial electron transport chain.

\section{Introduction}

The term congenital lactic acidosis is used to describe a group of rare inherited metabolic disorders in infants that is characterized by lactic acidemia. These conditions are accompanied to a variable degree by hyperalaninemia, hypoglycemia, neurologic impairment, and muscular hypotonia. The differential diagnosis of this group of disorders involves distinguishing among glycogen storage diseases $(1,2)$, organic acidemias (3), carnitine deficiency (4), primary deficiencies in the enzymes of gluconeogenesis (including pyruvate carboxylase [PC] ${ }^{1}$ $(5,6)$, phosphoenolpyruvate carboxykinase [PEPCK] $(7,8)$, and fructose 1,6-bisphosphatase [9]), defects in the pyruvate dehydrogenase complex (PDC) (10-12), pyridine nucleotide shuttle mechanisms (13), and defects in mitochondrial electron transport (14). Recently, there has been a brief report (15) of two infants in one family with congenital lactic acidosis associated with a defect in the functional activity of mitochondrial NADH-ubiquinone oxidoreductase (complex I). In the present report we describe studies of another infant with

1. Abbreviations used in this paper: $\mathrm{ACR}$, acceptor control ratio; $\mathrm{CoA}$, coenzyme A; EGTA, ethylene glycol bis ( $\beta$-aminoethyl ether)- $N, N, N^{\prime}, N^{\prime}$ tetraacetic acid; EPR, electron paramagnetic resonance; FCCP, carbonyl cyanide $p$-trifluoromethoxyphenylhydrazone; FMN, flavin mononucleotide; PC, pyruvate carboxylase; PDC, pyruvate dehydrogenase complex; PEPCK, phosphoenolpyruvate carboxykinase; RCR, respiratory control ratio; SMP, submitochondrial particle. 
congenital lactic acidosis caused by deficient activity of complex I. In this case it was found that the NADH-ferricyanide reductase activity of complex I per se was normal, but electron paramagnetic resonance spectroscopy showed that the deficiency in complex I was caused by a pronounced decrease in the reducible iron-sulfur clusters of complex $I$.

\section{Methods}

Case history. J.S. was a boy ( $2.2 \mathrm{~kg}$ ) born after a 34-wk gestation with decreased fetal activity; his mother was a gravida 2, para 1, 27-yr old Caucasian woman. There was no family history of consanguinity, birth defects, or infant deaths. There have been no similarly affected relatives, and a 1-mo-old male sibling is normal. The 5-min Apgar score was 8 after a Caesarean section for breech presentation. The child was noted to have a micropenis with grade II hypospadias. The karyotype was $46, \mathrm{XY}$.

The infant developed respiratory distress and was noted to be hypoglycemic $(17-22 \mathrm{mg} / \mathrm{dl})$ in the first $24 \mathrm{~h}$ of life. The hypoglycemia was managed with $20 \%$ dextrose and the respiratory distress improved. He was then placed on a proprietary milk formula for the rest of the hospitalization. At $3 \mathrm{wk}$ of age he developed weakening respiratory efforts which led to endotracheal intubation and ventilatory dependency for the remainder of his life. Routine blood analysis at this time revealed the following: sodium, 139; potassium, 4.6; chloride, 96; bicarbonate, 16; and anion gap, $27 \mathrm{meq} / \mathrm{liter}$, glucose, 99; blood ureanitrogen, 21; calcium, 10.2; phosphate, 3.4; and uric acid, $4.9 \mathrm{mg} / \mathrm{dl}$; lactate, $5 \mathrm{mM}$ (normal $<2.5 \mathrm{mM}$ ); and arterial $\mathrm{pH}, 7.30$. The urine was positive for ketone bodies.

At 6 wk of age the patient was transferred to the Neonatal Intensive Care Unit at Johns Hopkins Hospital. Physical examination revealed a grade III/VI blowing systolic heart murmur. Echocardiogram and cardiac catheterization revealed concentric biventricular hypertrophy consistent with a storage cardiomyopathy. Neurologic examination showed generalized hypotonia with weak movements and a poor sucking response. However, he responded to a sound and fixed and followed visually. Electroencephalogram, sonogram, and computerized tomographic scan of the brain were normal.

Although of normal size at $6 \mathrm{wk}$ of age, the liver had enlarged to $6 \mathrm{~cm}$ below the right costal margin by 12 wk. Serum aspartate aminotransferase was $414 \mathrm{IU} / \mathrm{liter}$ (normal, 0-41 IU/liter) and alanine aminotransferase was $181 \mathrm{IU} /$ liter (normal, 0-33 IU/liter). Cardiomegaly was also more prominent by $12 \mathrm{wk}$, with a decreased systolic ejection fraction as measured by echocardiogram. The infant became increasingly unresponsive neurologically and was no longer alert to visual or auditory stimuli. A repeat computerized tomographic scan and sonogram showed decreased density of the frontal and parietal white matter and ventriculomegaly. However, electroencephalograms did not show any abnormalities. An open liver and skeletal muscle biopsy was performed.

From 5-16 wk of age the patient was noted to have a progressive lactic acidemia, which increased from 5 to $31 \mathrm{mM}$ (Fig. 1). There was an elevated serum lactate/pyruvate ratio of 54 and 64 on two separate occasions (lactate, $17.2 \mathrm{mM}$; pyruvate, $0.32 \mathrm{mM}$; and lactate, 30.6 $\mathrm{mM}$; pyruvate, $0.48 \mathrm{mM}$, respectively; normal ranges; lactate, $0.5-2.5$ $\mathrm{mM}$; pyruvate, $0.05-0.10 \mathrm{mM}$; lactate/pyruvate ratio, 10-20). The plasma alanine level had increased from 1,140 to $2,300 \mu \mathrm{M}$ (normal, $<440 \mu \mathrm{M}$ ). The lactic acidemia required increasing bicarbonate supplements of up to $50 \mathrm{meq} / \mathrm{kg}$ per $\mathrm{d}$ to maintain arterial $\mathrm{pH}>7.25$. Despite a number of therapeutic strategies, including 1-2 wk trials of thiamine $(400 \mathrm{mg} / \mathrm{d})$, biotin $(10 \mathrm{mg} / \mathrm{d})$, carnitine $(660 \mathrm{mg} / \mathrm{d})$, and a

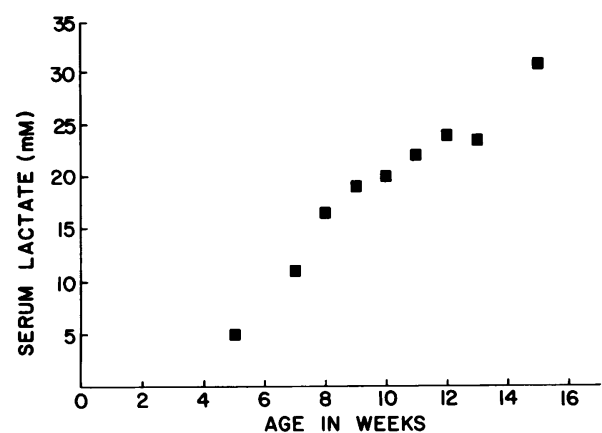

Figure 1. Serum lactate levels in patient between 5 and $15 \mathrm{wk}$ of age.

ketogenic diet (70\% fat), lactic acidemia persisted and the child died of cardiopulmonary arrest at $16 \mathrm{wk}$ of age.

A series of biochemical investigations was carried out during his hospital course to differentiate the various causes of congenital lactic acidosis. An 8-h fast resulted in an asymptomatic fall in serum glucose from 120 to $45 \mathrm{mg} / \mathrm{dl}$. The administration of glucagon $(10 \mu \mathrm{g} / \mathrm{kg})$ intramuscularly resulted in a rise in glucose from 45 to $150 \mathrm{mg} / \mathrm{dl}$ in $15 \mathrm{~min}$. An oral glucose tolerance test $(1.75 \mathrm{~g} / \mathrm{kg})$ did not result in a significant change in serum lactate (from 12.5 to $14.2 \mathrm{mM}$ ). Gas-liquid chromatography of the urine revealed an increased excretion of lactate, $\beta$-hydroxybutyrate, and acetoacetate. Smaller amounts of fumarate, oxalate, glutarate, and $p$-hydroxyphenyllactate were also noted. Total serum carnitine was $24.7 \mu \mathrm{M}$ (normal range, 43-52 $\mu \mathrm{M}$ ), with 11.1 $\mu \mathrm{M}$ free carnitine (normal range, 35-45 $\mu \mathrm{M}$ ) and $13.7 \mu \mathrm{M}$ esterified carnitine (normal range, $0-10 \mu \mathrm{M}$ ). The results of these studies failed to provide an explanation for the cause of the lactic acidosis.

To investigate the possibility of a defect in the primary pathways of pyruvate metabolism, a series of enzyme studies in both lymphocytes and fibroblasts was performed at 6-10 wk of age. The results are given in Table I. All determinations of PC, PEPCK, and PDC activities were normal to increased in fibroblasts and lymphocytes. Furthermore, the principal activating and inactivating (phosphorylation) mechanisms of the pyruvate dehydrogenase complex, elicited by dichloroacetate and fluoride, were normal.

PC, PEPCK, and PDC were also measured in the mitochondria, obtained from the postmortem liver material, as shown in Table I. The activity of each of these enzymes was somewhat less than the average found in controls, but all were within the range of control values. When the delay in assaying these samples is taken into account, the activities are not considered significantly reduced. It should be noted that full inactivation of the pyruvate dehydrogenase complex, which requires ATP, depended on the addition of succinate and ADP.

Activities of other key enzymes involved in gluconeogenesis were also measured in the liver biopsy material. Glucose 6-phosphatase (14 $\mathrm{nmol} / \mathrm{min}$ per $\mathrm{mg}$ liver homogenate; normal range, 5-14 nmol/min per $\mathrm{mg}$ ) and fructose 1,6-bisphosphatase $(59 \mathrm{nmol} / \mathrm{min}$ per $\mathrm{mg}$ microsomal supernatant; normal, range $45-65 \mathrm{nmol} / \mathrm{min}$ per $\mathrm{mg}$ ) activities were normal.

Light and electron microscopic examination of liver and skeletal muscle obtained at biopsy revealed an increased number of mitochondria in both tissues. Skeletal muscle tissue showed myofibrils distorted by accumulation of lipid and glycogen (Fig. $2 A$ ). Giant mitochondria containing both inner and outer membranes arranged in concentric whorls were noted throughout the skeletal muscle sections (Fig. $2 B$ and $C$ ). Occasional osmiophilic inclusions were noted in some mitochondria but there were no other atypical inclusions like those that 
Table I. Activities of Enzymes Involved in Pyruvate Metabolism*

\begin{tabular}{|c|c|c|c|}
\hline Source & $\begin{array}{l}\text { Enzyme } \\
\text { measured }\end{array}$ & Patient: & Controls§ \\
\hline \multirow[t]{2}{*}{ Lymphocytes } & PC & 0.213 & $0.154 \pm 0.028$ \\
\hline & PEPCK & 2.96 & $1.42 \pm 0.119$ \\
\hline \multirow[t]{5}{*}{ Skin fibroblasts } & PC & 2.72 & $0.94 \pm 0.43$ \\
\hline & PEPCK & 9.53 & $2.37 \pm 2.20$ \\
\hline & PDC & A 1.79 & $1.02 \pm 0.58$ \\
\hline & & B 4.84 & $2.46 \pm 0.80$ \\
\hline & & C 0.56 & $0.62 \pm 0.40$ \\
\hline \multicolumn{4}{|l|}{ Liver } \\
\hline \multirow[t]{6}{*}{ mitochondria } & PC & 118 & $240 \pm 94$ \\
\hline & PEPCK & 156 & $198 \pm 60$ \\
\hline & PDC" & A 4.30 & $8.74 \pm 6.4$ \\
\hline & & B 4.75 & $10.43 \pm 4.3$ \\
\hline & & C 3.16 & $6.05 \pm 4.5$ \\
\hline & & D 0.62 & ND \\
\hline
\end{tabular}

* Values represent nanomoles per minute per milligram protein. $\ddagger$ Values for patient's data indicate the mean of at least four replicate determinations.

$\S$ Values for control data indicate the mean \pm S.D. and number (in parentheses) of separate control patients.

"The PDC activities are as follows: A, untreated; B, dichloroacetate activated; $C$, sodium fluoride inactived; and $D$, inactivated by addition of ADP (2 mM), succinate $(10 \mathrm{mM})$, sodium fluoride $(15 \mathrm{mM})$ and phosphate $(10 \mathrm{mM})$. Liver mitochondria were isolated from autopsy material. have been described in previous cases of mitochondrial myopathies (14). Myocardial tissue examined at autopsy showed findings similar to those above, with myofibrils displaced to the periphery of the cell by excessive glycogen and lipid. It is interesting that the mitochondria present in the liver of the infant appeared normal in morphology, and no concentric membrane whorls were seen (not shown). However, there was an excessive accumulation of lipid and glycogen in the hepatocytes. Renal tubular cells also examined at autopsy showed an increased number of mitochondria that appeared normal but no accumulation of lipid or glycogen.

Isolation of mitochondria from liver and kidney. The samples for isolation of mitochondria from the patient were obtained as follows: A portion of the anterior lobe of liver and a portion of rectus abdominus were obtained by open biopsy, and portions of liver, heart, kidney, and psoas muscle were obtained within $\mathbf{4 0 ~} \mathrm{min}$ of death. These specimens were immediately placed into chilled $210 \mathrm{mM}$ mannitol, $70 \mathrm{mM}$ sucrose, $1 \mathrm{mM}$ ethylene glycol bis- $(\beta$-aminoethyl ether$N, N, N^{\prime}, N^{\prime}$-tetraacetic acid), (EGTA), $0.5 \%$ bovine serum albumin (BSA), $5 \mathrm{mM}$ HEPES at pH 7.2 (HEPES-medium plus EGTA). Samples of the same tissues were obtained from a 6-wk-old infant with spinal muscular atrophy of unknown etiology who died of respiratory insufficiency. This patient had no known metabolic disease, and the lactate level, $0.6 \mathrm{mM}$, was normal. Samples were trimmed of fat and connective tissue and finely minced with surgical scissors. The mitochondrial fractions were then isolated by differential centrifugation after homogenization (16). The final mitochondrial pellets were resuspended in HEPES-medium minus EGTA at a protein concentration of $20-40 \mathrm{mg} / \mathrm{ml}$. Excess aliquots that were not immediately used were stored at $-70^{\circ} \mathrm{C}$.

Isolation of heart and skeletal muscle mitochondria. Portions of the heart (left ventricle) and skeletal muscle (inferior psoas) obtained after death were finely minced with scissors in 1-2 ml of HEPESmedium plus EGTA. The finely minced tissue was passed through a hand-held tissue press and homogenized with a tight-fitting (0.15-0.23
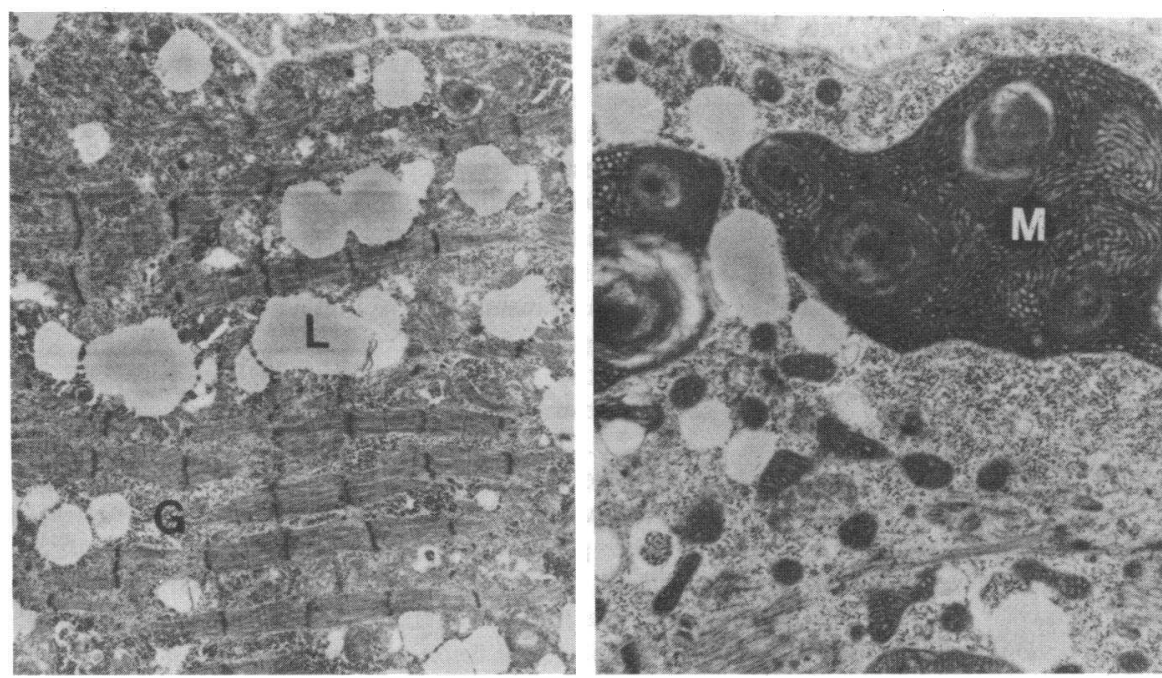

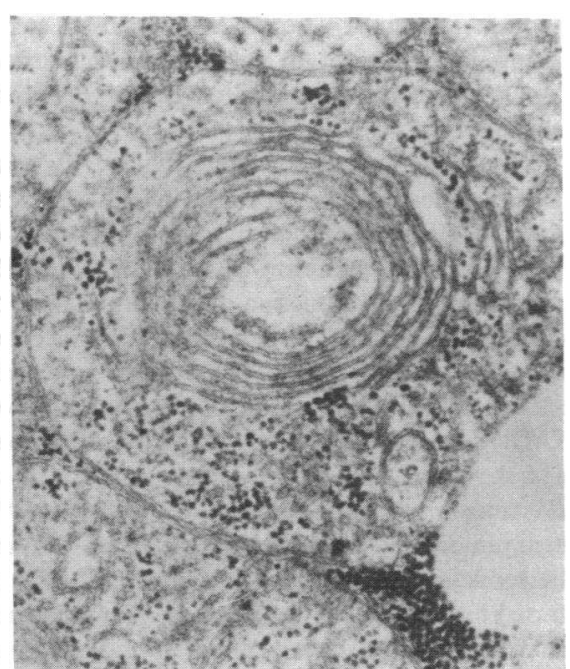

Figure 2. (A) Electron micrograph of skeletal muscle (7,000X; uranyl acetate and lead citrate). Note lipid accumulation (L) and abundant glycogen $(\mathrm{G})$ separating muscle fibers from one another. $(B)$ Electron micrograph of skeletal muscle $(15,000 \times$; uranyl acetate and lead citrate). Huge mitochondrion (M) with cristae forming whorls. $(C)$ Electron micrograph of skeletal muscle mitochondria with cristae forming concentric whorls and intramitochondrial glycogen $(24,000 \times$; uranyl acetate and lead citrate). 
mm clearance) teflon pestle in a glass homogenizer (17). Mitochondrial fractions were obtained by differential centrifugation as described for liver and kidney. The final mitochondrial pellets were resuspended to $14-20 \mathrm{mg}$ protein $/ \mathrm{ml}$ and unused portions were stored at $-70^{\circ} \mathrm{C}$.

Polarographic determinations of oxygen consumption. Oxygen consumption by the freshly isolated mitochondria was measured in a thermostatically closed oxygraph vessel of 1.52 (or 2.50 ) $\mathrm{ml}$ volume at $30^{\circ} \mathrm{C}$ by use of an oxygen electrode (Clark Microanalytic Laboratories, Urbana, IL). The oxygraph medium contained $130 \mathrm{mM} \mathrm{KCl}, 10 \mathrm{mM}$ morpholinopropanesulfonic acid, $2 \mathrm{mM} \mathrm{MgCl}, 2 \mathrm{mM} \mathrm{KH}_{2} \mathrm{PO}_{4}$, and $10 \mathrm{mM}$ respiratory substrate(s) at $\mathrm{pH} 7.2$. Oxygen consumption was initiated by the addition of mitochondria. Further additions to the chamber were made via syringe, as indicated in the appropriate figures. The solubility of oxygen in this medium was determined to be $455 \mathrm{ng}$ atoms $\mathrm{O} / \mathrm{ml}$ at $30^{\circ} \mathrm{C}$.

Enzyme assays. PC activity was measured in homogenates of lymphocytes, skin fibroblasts, and freeze-thawed mitochondria from liver and kidney obtained postmortem by determination of the pyruvatedependent fixation of $\left[{ }^{14} \mathrm{C}\right]$ bicarbonate in the presence of acetylcoenzyme A (CoA), ATP, and citrate synthase (5). PEPCK activity was measured similarly by inosine diphosphate-dependent fixation of $\left[{ }^{14} \mathrm{C}\right]$ bicarbonate in the presence of phosphoenolpyruvate, malate dehydrogenase, and NADH (5). Pyruvate dehydrogenase complex activity was determined as the thiamine pyrophosphate and CoA-dependent decarboxylation of $1-\left[{ }^{14} \mathrm{C}\right]$ pyruvate after activation or inactivation of the complex by pretreatment of intact cells or mitochondria with dichloroacetate or fluoride (12). In autopsy liver mitochondria the pyruvate dehydrogenase complex was alternatively inactivated by preincubation in the presence of $10 \mathrm{mM}$ succinate, $2 \mathrm{mM}$ adenosine diphosphate, $10 \mathrm{mM}$ phosphate, and $15 \mathrm{mM}$ sodium fluoride for 15 min at 37 C. Glucose-6-phosphatase was measured in the liver homogenate (18). Fructose-1,6-bisphosphatase was measured in the postmicrosomal supernatant (the supernatant after centrifugation at $105,000 \mathrm{~g}$ of liver homogenate) (9). The mitochondrial matrix enzyme activities were determined on dilutions of freeze-thawed aliquots of the various mitochondrial fractions, as described in reference 18 , in buffers supplemented with $0.05 \%$ Triton X-100 (except for citrate synthase, where $0.1 \%$ Lubrol WX was used) to ensure complete release of matrix activities. All enzyme determinations were performed in duplicate at various protein concentrations and all rates were linear with respect to time and protein.

NADH-cytochrome c reductase activity was measured on freezethawed mitochondria (followed by a 5-s sonication with a microtip probe at $40 \mathrm{~W}$ output with a sonifier [model W185; Branson Sonic Power Co., Div. Branson Ultrasonics Corp., Danbury, CT]) by the monitoring of the reduction of cytochrome $c$ at $550 \mathrm{~nm}$ (19) in a final volume of $3.1 \mathrm{ml}$ at $30^{\circ} \mathrm{C}$. When present, rotenone was added at a final concentration of $15 \mu \mathrm{M}$. The rotenone-sensitive rate of cytochrome c reduction was taken as the NADH-ubiquinone oxidoreductase activity. NADH-ferricyanide reductase activity of complex I was measured in a final volume of $3.19 \mathrm{ml}$ containing $50 \mathrm{mM}$ sodium phosphate, 10 $\mu \mathrm{M}$ rotenone, $1 \mu \mathrm{g}$ antimycin $\mathrm{A}, 1 \mathrm{mM} \mathrm{KCN}, 0.5 \mathrm{mM}$ potassium ferricyanide, and $0.6 \mathrm{mM} \mathrm{NADH}$ at $\mathrm{pH} 7.5$ and $30^{\circ} \mathrm{C}$ by following the reduction of ferricyanide at $410 \mathrm{~nm}$. The above reactions were started by addition of freshly freeze-thawed samples.

Preparation of submitochondrial particles for electron paramagnetic resonance (EPR) studies. Frozen liver mitochondria from the patient (650 $\mathrm{mg}$ protein) and normal liver mitochondria from the control (1.2 g protein) were thawed, diluted to $10 \mathrm{mg}$ protein/ml in medium A (10 mM Na+-HEPES, $1 \mathrm{mM} \mathrm{MgCl}_{2}, 1 \mathrm{mM} \mathrm{Na}{ }^{+}$-ATP, $5 \mathrm{mM} \mathrm{Na}^{+}$succinate, $0.2 \mathrm{mM} \mathrm{NADH}, 1 \% \mathrm{BSA}, \mathrm{pH} 7.1$ ), and centrifuged at
$15,500 \mathrm{rpm}$ for $10 \mathrm{~min}\left(1.6 \times 10^{5} \mathrm{~g} \times \min \right)$ at $4^{\circ} \mathrm{C}$. The supernatant was carefully removed and stored at $-20^{\circ} \mathrm{C}$. The pellet was resuspended to $\sim 20 \mathrm{mg}$ protein $/ \mathrm{ml}$ in medium $\mathrm{A}$ and $3-\mathrm{ml}$ aliquots were sonicated in an ice bath with four separate 30-s bursts (at 15-s intervals) at 80 W output with the sonifier outfitted with a microtip probe. The sonicated suspension was then centrifuged at $15,500 \mathrm{rpm}$ for $10 \mathrm{~min}$ and the cloudy amber supernatant was carefully removed without disturbing the lower unbroken pellet of mitochondria. The lower pellet of mitochondria was then resuspended and sonicated again as above, recentrifuged at $15,500 \mathrm{rpm}$, and the supernatant was combined with the original supernatant. The combined supernatants were centrifuged at $30,000 \mathrm{rpm}$ for $1 \mathrm{~h}$ in a rotor (Type 55.2; Beckman Instruments, Inc., Fullerton, CA) $\left(6.3 \times 10^{6} \mathrm{~g} \times \mathrm{min}\right)$. The supernatant fraction was removed and the dark reddish-brown pellet was resuspended in $250 \mathrm{mM}$ sucrose, $50 \mathrm{mM} \mathrm{Na}-$-HEPES, $\mathrm{pH} 7.5$, at $\sim 10 \mathrm{mg}$ protein/ $\mathrm{ml}$ and recentrifuged at $30,000 \mathrm{rpm}$ for $1 \mathrm{~h}$; the supernatant was removed and the dark reddish-brown pellet was carefully scraped from the tube with a closed-tip Pasteur pipette, avoiding the transfer of any light brown material from the lowest portion of the pellet. This material represents inner and outer mitochondrial membrane free of matrix enzymes and was gently resuspended to $40-48 \mathrm{mg} / \mathrm{ml}$ in $250 \mathrm{mM}$ sucrose, $50 \mathrm{mM} \mathrm{Na}{ }^{+}$-HEPES, pH 7.5, with a small glass homogenizer with a Teflon pestle for a final yield of $10-12 \%$ membrane protein from starting material.

Samples $(250 \mu \mathrm{l})$ for EPR measurements were prepared by the following procedures to manipulate the redox state of the iron-sulfur clusters: (a) reduction by $4 \mathrm{mM}$ NADH; $(b)$ reduction by $10 \mathrm{mM}$ succinate; $(c)$ reduction by $4 \mathrm{mM} \mathrm{NADH}$ in the presence of rotenone $(0.1 \mathrm{nmol} / \mathrm{mg}) ;(d)$ oxidation by $1 \mathrm{mM}$ ferricyanide; and $(e)$ reduction by $10 \mathrm{mM}$ dithionite. Sample $c$ was preincubated with rotenone for $10 \mathrm{~min}$ before the addition of NADH. All samples also contained 2.5 $\mu \mathrm{M}$ carbonyl cyanide p-trifluoromethoxyphenylhydrazone (FCCP) (added as a dimethylsulfoxide solution, final dimethylsulfoxide was $0.25 \%$ ). After the addition of the reductant or oxidant the samples were transferred to matched quartz EPR tubes $(\sim 3 \mathrm{~mm}$ internal diameter), incubated for 3-5 $\mathrm{min}$ at room temperature, and then frozen at $81 \mathrm{~K}(21)$. The samples were then stored in liquid nitrogen until spectra could be obtained.

EPR spectroscopy. EPR measurements were conducted with a spectrometer (E109; Varian Associates Instrument Group, Palo Alto, CA). Sample temperature was controlled by use of a variable temperature, helium flow cryostat system (LTD-3-110; Airproduct, Allentown, PA). The temperature was monitored with an Allen-Bradley (Milwaukee, WI) type carbon resistor located $\sim 1 \mathrm{~cm}$ below the sample. The magnetic field was calibrated with a weak pitch gauss value standard (Varian Associates, Instrument Group). Further EPR conditions are described in the appropriate figure legends.

Protein determination, spectrophotometric measurements, and reagents. Protein was determined by a modified Lowry procedure (22) with BSA as standard. Flavin mononucleotide (FMN) was measured fluorometrically in freeze-thawed liver mitochondria (23). Pyridine nucleotides were measured as described in (18). All spectrophotometric determinations were performed on a recording spectrophotometer (model 240; Gilford Instrument Laboratories, Inc., Oberlin, OH). Reagents were obtained from commercial suppliers and were analytical grade prepared in distilled and deionized water.

\section{Results}

The results of the studies detailed above eliminated most of the previously described causes of congenital lactic acidosis. 
We therefore investigated the remaining possibility of a defect in mitochondrial function, which was suggested by the increased lactate/pyruvate ratios. Fig. 3 is a schematic diagram of our present understanding of the respiratory chain of the inner mitochondrial membrane. The organization of the electron transport chain and the availability of specific inhibitors for various segments of the chain allow a systematic investigation of pathways of electron transport from different respiratory substrates.

Mitochondrial respiration on succinate. Fig. $4 A$ shows that electron transport and energy coupling were normal when succinate, which is oxidized via complexes II, III and IV, was the respiratory substrate. Mitochondrial oxygen consumption was stimulated by ADP, inhibited by oligomycin (a specific inhibitor of the mitochondrial ATPase), and restimulated by the addition of an uncoupler (FCCP). The calculated acceptor control ratio (ACR; rate of ADP-stimulated respiration divided by the oligomycin-inhibited rate) was $\sim 3$ and the respiratory control ratio (RCR; rate of FCCP-stimulated respiration divided by the oligomycin-inhibited rate) was $\sim 10$. These values were very similar to those obtained with the control liver mitochondria, as shown in Fig. $4 B$, and demonstrated that the respiratory chain from succinate dehydrogenase to coenzyme $Q$ and from there to cytochrome oxidase (see Fig. 3) was functionally intact in this patient's liver mitochondria. Furthermore, the transmembrane transport of ADP, phosphate, and ATP was normal, as evidenced by the high ACR.

$N A D^{+}$-linked mitochondrial respiration. When respiration on $\mathrm{NAD}^{+}$-linked substrates was examined an anomalous result was obtained, as shown in Fig. $5 A$. With the combined $\mathrm{NAD}^{+}$-linked substrates malate plus glutamate there was little stimulation of respiration in the patient's liver mitochondria after the addition of ADP or FCCP, whereas the control liver mitochondria gave the expected stimulation of respiration (Fig. $5 B$ ). This deficiency was even more striking in the mitochondria from skeletal muscle from the patient (Fig. $5 C$ ) as compared with control (Fig. $5 \mathrm{D}$ ). The addition of ADP or FCCP to skeletal muscle mitochondria barely altered the already low rate of oxygen consumption. Results virtually identical to those in Fig. 5, $A$ and $C$ were obtained with a variety of $\mathrm{NAD}^{+}$-linked substrates, which included $\alpha$-ketoglutarate, pyruvate plus malate, citrate, and isocitrate (data not shown). Thus, the observations of the patient's mitochondria demonstrated a deficiency of NAD ${ }^{+}$-linked respiration, whereas respiration with succinate was unaffected.

Table II compares the results of mitochondrial respiration studies in liver, kidney, heart, and skeletal muscle mitochondria obtained postmortem from the patient versus the normal controls. It is evident that low absolute rates of $\mathrm{NAD}^{+}$-linked respiration were present in the patient's mitochondria under both phosphorylating (ADP present, A-III) and uncoupled (FCCP present, F-III) conditions, whereas succinate-linked respiration was very similar to the control. These low rates of respiration were reflected in low ACR and RCR values and were particularly striking in skeletal muscle mitochondria where there was virtually no $\mathrm{NAD}^{+}$-linked respiration. Based on comparisons with the normal control tissues, the defect in $\mathrm{NAD}^{+}$-linked respiration appeared to be severe in skeletal

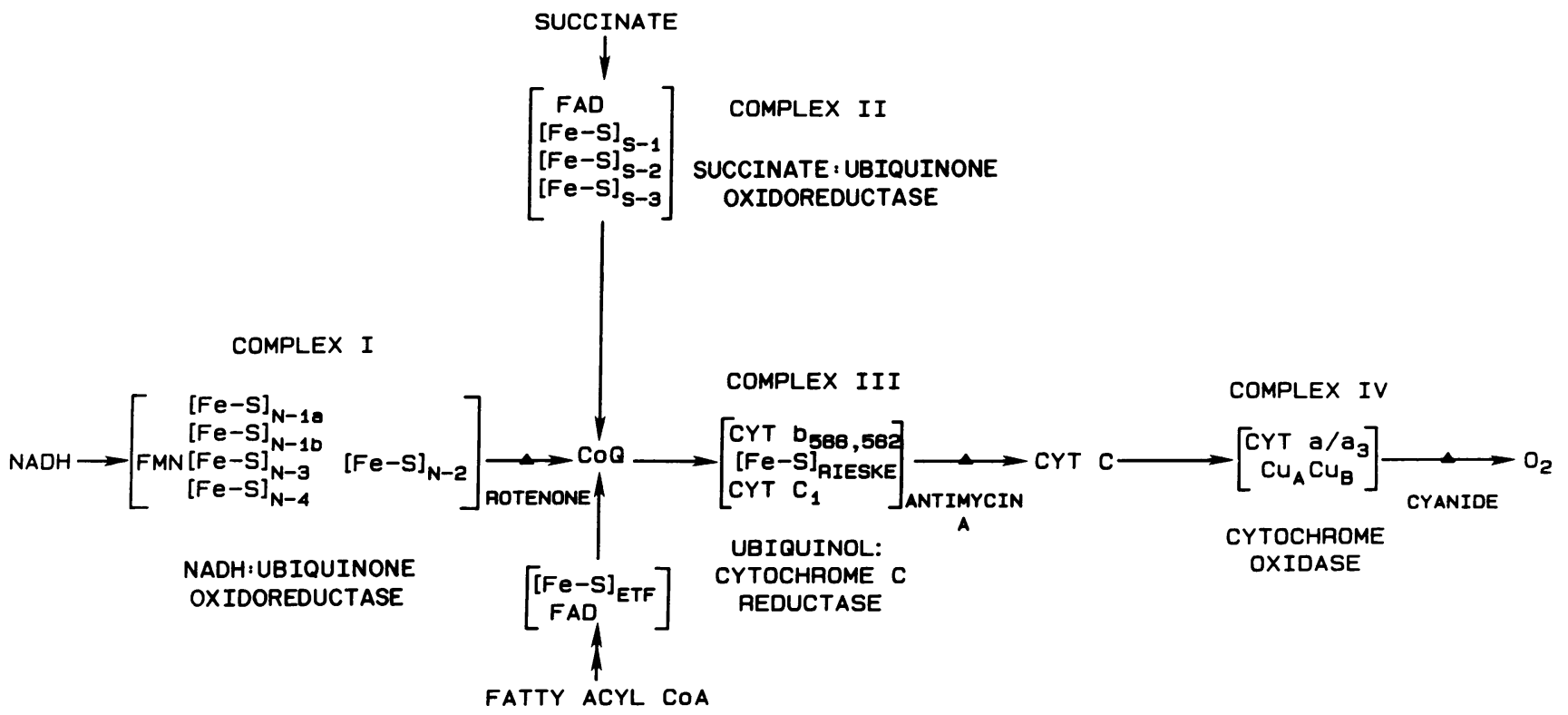

Figure 3. Schematic representation of the electron transport components of the inner mitochondrial membrane. Arrows indicate the flow of electrons from substrates through the various components of the respiratory chain. Heavy arrows indicate the sites of inhibition by the principle inhibitors. 


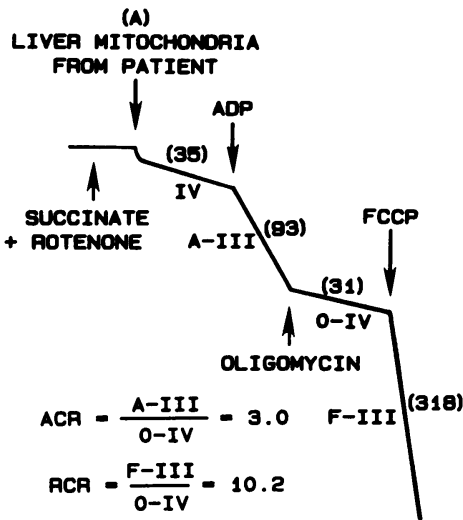

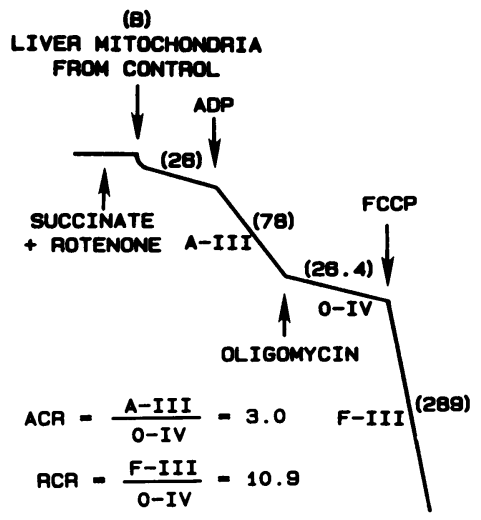

Figure 4. Flavin adenine dinucleotide-linked mitochondrial respiration. Liver mitochondria from the patient $(A)$ and control $(B)$ were resuspended at $1 \mathrm{mg} / \mathrm{ml}$ as described in Methods. The final concentrations of the indicated additions were: ADP, $0.4 \mathrm{mM}$; oligomycin, $2 \mu \mathrm{g} / \mathrm{mg}$ protein; and FCCP, $0.15 \mathrm{nmol} / \mathrm{mg}$ protein. Numbers in parentheses represent rates of oxygen consumption in nanogram atoms $O$ per minute per milligram mitochondrial protein. muscle, heart, and liver mitochondria but less evident in the kidney mitochondria, where reasonably high ACR and RCR values were observed.

The biochemical basis for defective $\mathrm{NAD}^{+}$-linked respiration. A deficiency in NAD $^{+}$-linked mitochondrial respiration could arise from several conditions: $(a)$ a deficiency of the relevant membrane transport systems for entry of the various $\mathrm{NAD}^{+}$linked respiratory substrates; $(b)$ a deficiency of the relevant dehydrogenases (and ancillary enzymes) involved in reduction of matrix $\mathrm{NAD}^{+}$; (c) inadequate levels of $\mathrm{NAD}(\mathrm{P})^{+}$in the mitochondrial matrix; and $(d)$ a deficiency in the NADHubiquinone oxidoreductase system, i.e., complex I of the respiratory chain.

The results of $\mathrm{O}_{2}$ consumption studies suggested that at least four separate and distinct transport proteins of the inner mitochondrial membrane (the pyruvate, $\alpha$-ketoglutarate, tricarboxylate, and electrogenic glutamate/aspartate translocases [24]) would have to be deficient in order to consistently explain
(A)

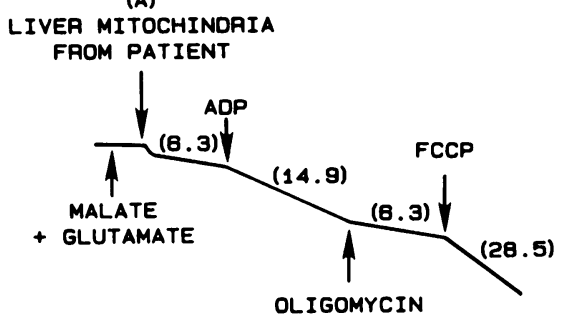

(C)

SKELETAL MUSCLE

MITOCHONDRIA FROM PATIENT

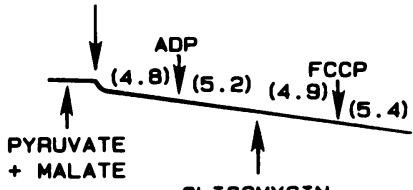

OLIGOMYCIN
(B)

LIVER MITOCHONDRIA

FROM CONTROL

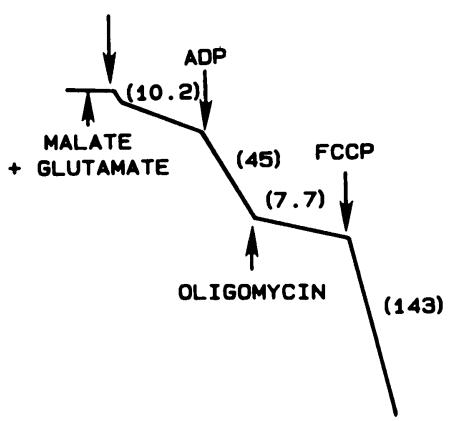

(D)

SKELETAL MUSCLE

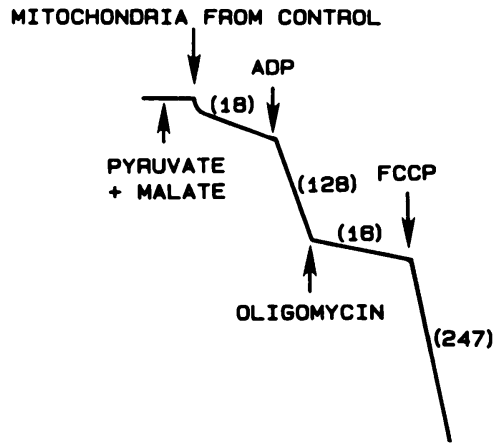

Figure 5. $\mathrm{NAD}^{+}$-linked mitochondrial respiration. Liver and skeletal muscle mitochondria obtained from autopsy material were resuspended at $1 \mathrm{mg} / \mathrm{ml}$ as described in Methods. The indicated additions were as described in Fig. 4. ( $A$ ) ADP + FCCP addition yielded little stimulation and respiration in patient's liver mitochondria as compared with control $(B)$, or in the patient's skeletal muscle mitochondria $(C)$ as compared with control $(D)$. Numbers in parentheses represent rates of respiration in nanogram atoms $O$ per minute per milligram mitochondrial protein. 
Table II. Oxygen Consumption by Mitochondria of the Patient and Control Respiring with Various Substrates

\begin{tabular}{|c|c|c|c|c|c|c|}
\hline \multirow{2}{*}{$\begin{array}{l}\text { Source of } \\
\text { mitochondria }\end{array}$} & \multirow[b]{2}{*}{ Respiratory substrate } & A-III & O-IV & F-III & \multirow[b]{2}{*}{ ACR } & \multirow[b]{2}{*}{ RCR } \\
\hline & & \multicolumn{3}{|c|}{ ng atoms $0 /$ min per mg mitochondrial protein } & & \\
\hline \multirow[t]{3}{*}{ Liver } & Malate/glutamate & $14.9(45.0)$ & $6.3(7.7)$ & $28.5(143.0)$ & $2.3(5.8)$ & $4.5(18.6)$ \\
\hline & Pyruvate/malate & $13.0(51.2)$ & $6.0(6.6)$ & $27.0(114.7)$ & $2.1(7.8)$ & $4.5(17.4)$ \\
\hline & Succinate + rotenone & $93.0(78.0)$ & $31.0(26.4)$ & $318.0(289.0)$ & $3.0(3.0)$ & $10.2(10.9)$ \\
\hline \multirow[t]{3}{*}{ Kidney } & Malate/glutamate & $52.0(164.0)$ & $9.1(16.6)$ & $101.4(312.0)$ & $5.7(9.9)$ & $11.1(18.8)$ \\
\hline & Pyruvate/malate & $36.4(137.0)$ & $9.1(21.3)$ & $75.4(243.0)$ & $4.0(6.4)$ & $8.3(11.4)$ \\
\hline & Succinate + rotenone & $112.0(227.0)$ & $31.2(39.4)$ & $286.0(382.0)$ & $3.6(5.8)$ & $9.2(9.7)$ \\
\hline \multirow[t]{3}{*}{ Heart } & Malate/glutamate & $57.2(344.0)$ & $18.5(21.5)$ & $89.7(385.0)$ & $3.1(16.0)$ & $4.8(17.9)$ \\
\hline & Pyruvate/malate & $53.0(272.0)$ & $17.0(23.3)$ & $82.0(512.0)$ & $3.1(11.7)$ & $4.8(22.0)$ \\
\hline & Succinate + rotenone & $309.0(389.0)$ & $114.0(53.0)$ & $300.0(389.0)$ & $2.7(7.3)$ & $2.6(7.3)$ \\
\hline \multirow[t]{3}{*}{ Skeletal muscle } & Malate/glutamate & $5.0(98.5)$ & $4.9(13.7)$ & $5.0(256.0)$ & $1.0(7.2)$ & $1.1(18.7)$ \\
\hline & Pyruvate/malate & $5.2(128.0)$ & $4.9(16.0)$ & $5.4(247.0)$ & $1.0(8.0)$ & $1.1(15.4)$ \\
\hline & Succinate + rotenone & $110.0(144.0)$ & $37.3(32.0)$ & $264.0(215.0)$ & $3.0(4.5)$ & $7.1(6.7)$ \\
\hline
\end{tabular}

The different respiratory states are designated as follows: A-III, state III rate of respiration after addition of $0.4 \mathrm{mM}$ adenosine diphosphate; $\mathrm{O}-$ IV, state IV respiration after addition of $2 \mu \mathrm{g}$ oligomycin/mg protein to A-III; and F-III, uncoupled respiration after addition of 0.2-0.4 nmol FCCP/mg protein to F-III. ACR and RCR are defined in the text. Numbers in parentheses are the corresponding values obtained with the control mitochondria. Mitochondria were isolated from autopsy material.

all of the respiration data. This is apparent from examination of the data revealing low rates of respiration for all the $\mathrm{NAD}^{+}$. linked substrates including pyruvate (plus malate), $\alpha$-ketoglutarate, isocitrate and citrate, and glutamate (plus malate). Thus, with the present knowledge of these specific transport systems, plus other data (below), we considered it unlikely that a multiple deficiency of membrane transport systems was the cause of the observed deficiency in respiration.

To investigate possible deficiencies in tricarboxylic acid cycle enzymes, we assayed several matrix dehydrogenases as well as enzymes associated with anaplerotic generation of tricarboxylate cycle intermediates (results not shown). Their activities were virtually identical to control values and we therefore concluded that no deficiencies of the relevant tricar- boxylate cycle enzymes were apparent. Furthermore, total mitochondrial pyridine nucleotides were essentially normal in liver $(1.34 \mathrm{nmol} / \mathrm{mg}$ mitochondrial protein vs. $1.68 \mathrm{nmol} / \mathrm{mg}$ in the control mitochondria).

Since complex III appears to be fully active in the patient (succinate oxidation normal), the NADH-ubiquinone oxidoreductase (complex I) activity was measured in permeabilized mitochondria by determination of NADH-cytochrome c oxidoreductase (i.e., complex I + III) activity in the presence and absence of rotenone, a specific inhibitor of electron transport through complex I. The rotenone-sensitive rates were used as estimates of the complex I activity. Table III shows that the rates of rotenone-sensitive NADH-cytochrome c reductase activity are profoundly decreased in the treated mitochondria

Table III. Determinations of NADH-Cytochrome c Reductase Activities* in Permeabilized Mitochondria

\begin{tabular}{|c|c|c|c|c|c|c|c|}
\hline & \multicolumn{2}{|c|}{ Minus rotenone } & \multicolumn{2}{|c|}{ Plus rotenone } & \multicolumn{2}{|c|}{ Rotenone-sensitive activity } & \multirow{2}{*}{$\begin{array}{l}\text { Percentage of } \\
\text { control activity }\end{array}$} \\
\hline & Patient & Control & Patient & Control & Patient & Control & \\
\hline Kidney & 88 & 319 & 53 & 212 & 35 & 107 & 33 \\
\hline Liver & 216 & 341 & 201 & 210 & 15 & 131 & 11 \\
\hline Skeletal muscle & 117 & 335 & 112 & 129 & 5 & 206 & 2 \\
\hline
\end{tabular}

* Values represent rates of cytochrome $\mathrm{c}$ reduction in nanomoles per minute per milligram mitochondrial protein. Rotenone-sensitive NADHcytochrome $\mathrm{c}$ reductase activity was calculated from the difference in rates of cytochrome $\mathrm{c}$ reduction in the absence and presence of rotenone. The rotenone-insensitive NADH-cytochrome $c$ reductase activity is due to the outer membrane NADH-cytochrome $b_{5}$ reductase (19). Mitochondria were obtained from autopsy material and assayed as described in the Methods section. 
from the patient, ranging from only $2 \%$ of the control rates in skeletal muscle mitochondria to $33 \%$ in kidney mitochondria. These data demonstrate a remarkable decrease in the functional activity of complex I of the inner membrane, with the severity of inhibition closely parallel to the $\mathrm{O}_{2}$ uptake data reported in Table II.

In addition, measurements of succinate-cytochrome c reductase (complexes II and III) activity were performed (data not shown). These values were only slightly less than the control in heart, kidney, and skeletal muscle mitochondria but were normal in liver mitochondria; this is again consistent with the $\mathrm{O}_{2}$ uptake data in Table II which show that the biochemical lesion is proximal to ubiquinone reduction and thus resides in the rotenone-sensitive pathway of complex $I$.

$N A D H$-ubiquinone oxidoreductase activity using ferricyanide as an artificial electron acceptor. The activity of complex I was then measured with the artificial electron acceptor ferricyanide (25), which can accept electrons directly from the reduced FMN cofactor and is therefore insensitive to rotenone (26), which is believed to inhibit electron transfer from FMN to ubiquinone via the iron-sulfur clusters of complex I. The measurements were made on freeze-thawed mitochondria and on inverted submitochondrial membrane particles from liver, since ferricyanide cannot penetrate the intact inner membrane. Table IV shows that the NADH-ferricyanide reductase activities of such preparations were virtually identical to those of normal controls in all tissues of the affected infant except kidney. (The low rate in kidney mitochondria of the patient is directly attributable to the relatively low rate of rotenone-insensitive NADH-cytochrome $b_{5}$ reductase (19), which is also reactive with ferricyanide; see also Table III.) These data showed that electrons from NADH could reduce the bound flavin cofactor of complex I at a normal rate. Furthermore, since the FMN content of the patient's and control liver mitochondria were found to be identical $(0.16 \mathrm{nmol} / \mathrm{mg}$ mitochondrial protein $)$, the protein components of complex I that catalyze transfer of reducing equivalents from NADH to FMN were probably normal. Therefore, the lesion in complex I was more specifically localized and determined to lie between FMN and ubiquinone.

Table IV. NADH-Ferricyanide Reductase Activities* in Mitochondria and Submitochondrial Particles (SMPs)

\begin{tabular}{lll}
\hline Source & Patient & Control \\
\hline Heart & 2,505 & 2,550 \\
Kidney & 1,421 & 2,140 \\
Liver & 1,654 & 1,635 \\
Skeletal muscle & 1,306 & 1,405 \\
Liver SMPs & 3,840 & 4,280
\end{tabular}

\footnotetext{
* Values represent nanomoles ferricyanide reduced per minute per milligram mitochondrial protein. Mitochondria were obtained from autopsy material, frozen at $-70^{\circ} \mathrm{C}$, and assayed immediately after thawing in an ice bath, as described in the Methods section.
}

An examination of Fig. 3 strongly suggests that the biochemical lesion is in the series of iron-sulfur clusters of complex $I$.

Molecular basis for the defect in complex I. To investigate the possibility that the iron-sulfur clusters of complex I were the site of the lesion, submitochondrial particles (SMPs) were prepared from the liver mitochondria of the patient. SMPs are used for EPR spectroscopy of the iron-sulfur clusters since the mitochondrial matrix contains iron-sulfur cluster of aconitase, which interferes with EPR signals of the iron-sulfur cluster S-3 of the mitochondrial respiratory chain. As illustrated in Fig. 3, at least five iron-sulfur clusters, namely, N-1a, N-1b, $\mathrm{N}-2, \mathrm{~N}-3$, and $\mathrm{N}-4$ function as intrinsic electron transport components in complex I. These iron-sulfur clusters are paramagnetic in the reduced state and can be selectively reduced with NADH in rotenone-inhibited SMPs $(27,28)$.

Fig. 6 shows the EPR spectra corresponding to individual iron-sulfur clusters of complex I examined at appropriate sample temperatures by use of the differences in their spin relaxation behavior. At $30 \mathrm{~K}$, signals from cluster $\mathrm{N}-1 \mathrm{~b}$ $(\mathrm{g}=2.03, \mathrm{~g}=1.94)$ and the iron-sulfur clusters in the outer membrane $\left(\mathrm{g}_{\mathrm{x}}=2.01, \mathrm{~g}_{\mathrm{y}}=1.94, \mathrm{~g}_{\mathrm{z}}=1.89\right)$ are detected (spectrum A). Cluster $\mathrm{N}-1 \mathrm{~b}$ in the normal control (solid line), and the patient's liver SMPs (dashed line) can be selectively compared by use of the signal at $\mathrm{g}=2.03$ without interference from the other clusters. Cluster N-1b in the patient's SMPs is markedly diminished as evidenced by the absence of the positive peak at $\mathrm{g}=2.03$. Similarly, at the $12 \mathrm{~K}$ cluster $\mathrm{N}-2$ can be measured by the use of the signal with the negative peak at the $g$ value of 1.92 (spectrum B). At this temperature overlapping EPR signals from cluster S-3 (of succinate-ubiquinone oxidoreductase) obscure the $g=2.05$ signal. Nonetheless, the N-2 signal in the patient's SMPs is virtually absent. At $8 \mathrm{~K}$, clusters $\mathrm{N}-3$ and $\mathrm{N}-4$ are selectively observed (spectrum C) and can be compared with those of the control system by use of the $\mathrm{g}_{\mathrm{x}}=1.86\left(\mathrm{~N}-3\right.$ signal) and $\mathrm{g}_{\mathrm{y}}=2.10(\mathrm{~N}-4$ signal $)$ signals, which are outside the magnetic field of the overlapping S-3 spectrum. Again, centers N-3 and N-4 in the patient are virtually undetectable. The difference between the control and patient's spectra is given below the individual spectra and shows the pure iron-sulfur spectra of complex I with some residual signals from the outer membrane cluster. The results of these studies indicate either that the iron-sulfur clusters in complex I that are reducible by NADH in the presence of rotenone are greatly diminished or that the centers are present but not reducible by NADH and thus inactive.

Fig. 7 presents EPR spectra of the iron-sulfur clusters in the patient's SMPs reduced with succinate (dashed line) or dithionite (solid line) and recorded at three different temperatures. Dithionite is a nonspecific reducing agent able to chemically reduce all the iron-sulfur clusters of SMPs; it was employed to determine whether the deficiency of one or more of the clusters was due primarily to the failure of NADH to reduce them enzymatically. Most EPR signals observed at 30 $\mathrm{K}$ (spectrum $\mathrm{A}$ ) are due to cluster $\mathrm{S}-1$ of succinate-ubiquinone 
A

(30K)
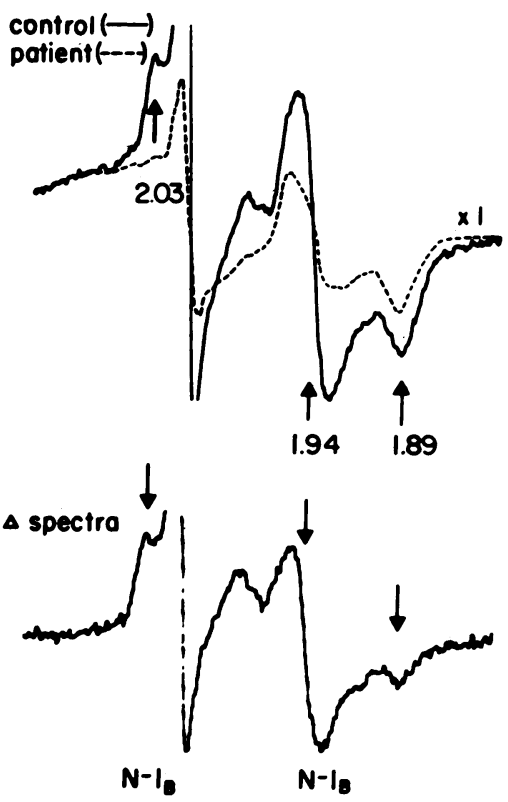

$0 . \longdiv { 3 2 }$
B

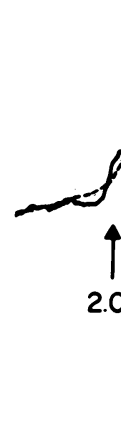

$(12 K)$

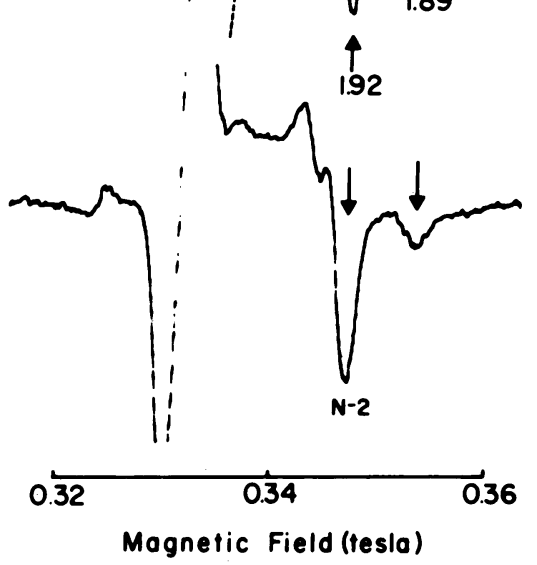

C

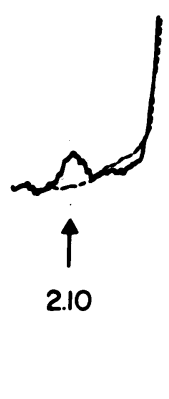

(8K)

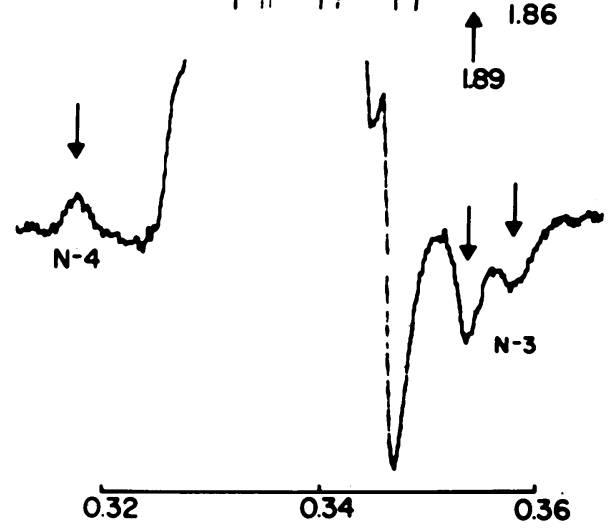

Figure 6. EPR spectroscopy of iron-sulfur clusters in the NADHubiquinone oxidoreductase segment of the respiratory chain. SMPs from the patient (dashed line) and the control (solid line) were preincubated with rotenone $(0.1 \mathrm{nmol} / \mathrm{mg}$ protein) for $10 \mathrm{~min}$ before reduction with $4 \mathrm{mM}$ NADH. Spectra $A, B$, and $C$ were recorded at

oxidoreductase; dithionite addition intensified the S-1 spectrum by $\sim 20 \%$. However, no N-1b center of complex I was revealed by chemical reduction. At $12 \mathrm{~K}$, EPR signals arising from the electron transfer flavoprotein dehydrogenase functional in the flavin-linked dehydrogenation of fatty acids were observed at $\mathrm{g}$ values of $2.08, \sim 1.94$, and 1.89 (spectrum B). Only a trace of iron-sulfur center $\mathrm{N}-2$ was detected at the $\mathrm{g}=2.05$ position upon addition of dithionite. No significant signals from $\mathrm{N}-3$ and $\mathrm{N}-4$ clusters at $8 \mathrm{~K}$ (spectrum $\mathrm{C}$ ) were seen after dithionite reduction, although there was some line-shape change around $\mathrm{g}=1.91$, which probably arises from spin-coupling between S-1 and S-2 (29). Dithionite addition to the control SMPs under the same conditions resulted in reduction of the ironsulfur clusters characteristic of complex I already seen in Fig. 6 (data not shown).

The combined results of the EPR studies presented in Figs. 6 and 7 demonstrate that in the patient's SMPs the concentrations of reducible iron-sulfur redox clusters of complex I are much lower than the control. Since the functional activities of the iron-sulfur clusters of complexes II and III, as well as the sample temperatures of 30,12 , and $8 \mathrm{~K}$ with microwave power levels of 2,1 , and $5 \mathrm{~mW}$, respectively. The EPR recording conditions were: modulation amplitude, $1.25 \times 10^{-3}$ tesla; time constant $0.128 \mathrm{~s}$ for 30 and $8 \mathrm{~K}$, and $0.064 \mathrm{~s}$ for $12 \mathrm{~K}$; scanning rate, $2.5 \times 10^{-2}$ tesla/ $\min$ for $30 \mathrm{~K}$ and $8 \mathrm{~K}, 5.0 \times 10^{-2}$ tesla/min for $12 \mathrm{~K}$.

characteristic EPR iron-sulfur signals of complex II, were essentially normal in mitochondrial preparations from the patient, the observed deficiency of iron-sulfur clusters in the mitochondria of the patient was not a generalized deficiency of all mitochondrial iron-sulfur clusters but was limited to those of complex $I$.

\section{Discussion}

The investigation of possible etiologies for this infant's progressive myopathy and lactic acidosis ruled out glycogen storage diseases, organic acidemias, systemic carnitine deficiency, and deficiencies in some of the enzymes concerned in pyruvate metabolism and gluconeogenesis. Further studies revealed a deficiency in oxidation of $\mathrm{NAD}^{+}$-linked substrates by mitochondria isolated from a number of tissues but no deficiency in the oxidation of succinate. The most affected tissue was skeletal muscle, in which oxidation of $\mathrm{NAD}^{+}$-linked substrates was virtually absent and could not be stimulated by either ADP or FCCP. The disorder was generalized, as evi- 


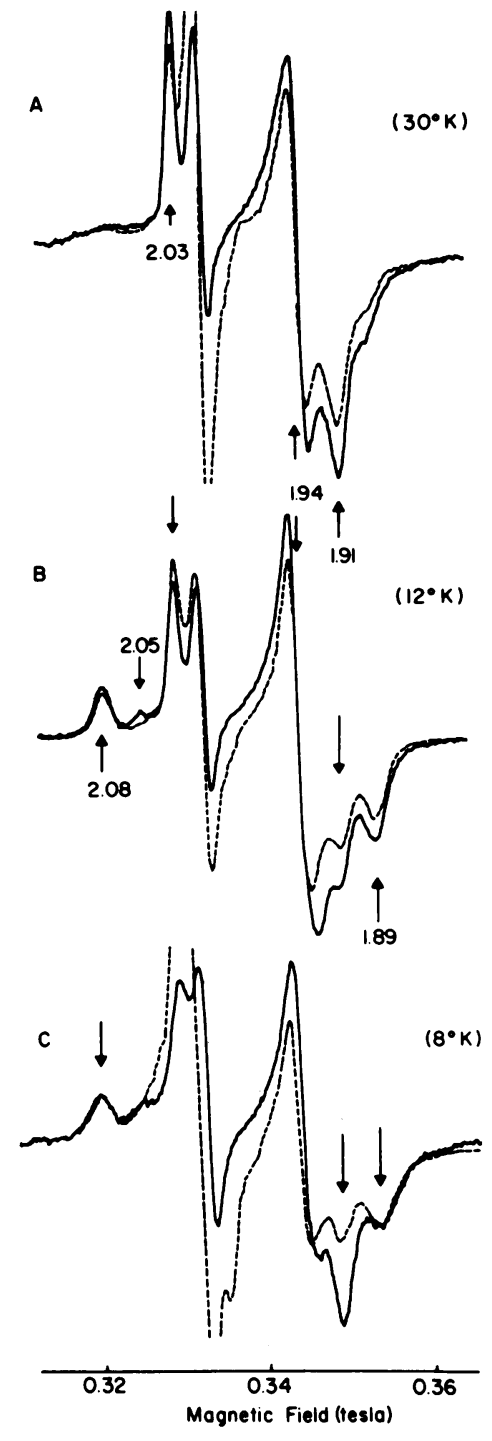

Figure 7. EPR spectra of the patient's SMPs reduced with $10 \mathrm{mM}$ succinate (dashed line) or $10 \mathrm{mM}$ dithionite (solid line) and recorded at three different temperatures. Sample temperatures, microwave power, and other EPR conditions were exactly as described in Fig. 6.

denced by low rates of $\mathrm{NAD}^{+}$-linked respiration in heart, liver, and kidney. This conclusion was further supported by measurements of NADH-cytochrome c reductase activity, which demonstrated a functional activity in complexes I + III ranging from only $2 \%$ (skeletal muscle) to $33 \%$ (kidney) of control values. Further, EPR determinations on liver submitochondrial particles revealed a virtual absence of the iron-sulfur clusters characteristic of complex I in the patient, but normal signals for other iron-sulfur clusters of mitochondria. The absence of its iron-sulfur clusters would render complex I unable to transfer electrons from the reduced FMN to ubiquinone (see Fig. 3), thus effectively shutting off $\mathrm{NAD}^{+}$-linked respiration, which normally makes up most of total respiratory activity. We propose that the underlying mechanism of this patient's disease was a congenital deficiency of iron-sulfur clusters in complex I.
Deficient complex I activity would explain the varied clinical, biochemical, and histological manifestations in this patient. These included elevated blood lactate and pyruvate (with increased lactate/pyruvate ratios), hypoglycemia, hyperalaninemia, cardiomyopathy, peripheral myopathy, and central nervous system dysfunction. Histologic findings included abnormal accumulations of tissue glycogen and abnormal mitochondrial structures.

The lactic acidosis indicates an inability to oxidize pyruvate derived from glucose and amino acids, with a resultant accumulation of lactate and alanine. We think that this diversion of respiratory substrates is a consequence of the decreased ability to oxidize a number of $\mathrm{NAD}^{+}$-linked substrates. The influx of $\mathrm{NAD}^{+}$-linked substrates into the tricarboxylate cycle and the compromised ability of the mitochondria to reoxidize $\mathrm{NADH}$ at an adequate rate would lead to a more reduced state of the intramitochondrial $\mathrm{NAD}^{+}$and $\mathrm{NADP}^{+}$, which could be expected to affect, directly or indirectly, the flux through several key enzymes of the mitochondria, including the pyruvate dehydrogenase complex, isocitrate dehydrogenase, citrate synthase, malate dehydrogenase, and $\beta$-hydroxyacylCoA dehydrogenase. The net effect of the failure of the reoxidation of NADH and the consequent increase in the NAD(P)H/NAD(P) ${ }^{+}$ratio would be to decrease catabolic tricarboxylate cycle activity and increase certain biosynthetic activities. Thus, incoming pyruvate would be shunted out of the mitochondria primarily as alanine (via alanine aminotransferase) or carboxylated to produce oxaloacetate (via pyruvate carboxylase). The oxaloacetate would then be converted to malate (via reversal of malate dehydrogenase due to elevated NADH), which would leave the mitochondria and enter the gluconeogenic pathway to be stored as glycogen. In addition, the normal operation of the malate-aspartate shuttle would be compromised; thus, the lactate dehydrogenase reaction must assume the cytosolic burden for the regeneration of $\mathrm{NAD}^{+}$for glycolysis, resulting in an almost quantitative conversion of glucose to lactate. The abnormal accumulations of lipid probably represent storage due to an inability to oxidize fatty acids completely. Thus, the compromised ability of the mitochondria to oxidize $\mathrm{NAD}^{+}$-linked substrates can cause a profound disturbance in the metabolism of carbohydrate, fat, and some amino acids. Moreover, inadequate synthesis of ATP by oxidative phosphorylation would result.

Complex I contains many molecular components arranged into a tightly bound cluster or complex (30): 25 polypeptide chains, FMN, and 9 iron-sulfur centers, of which 6 are binuclear $(2 \mathrm{Fe}$ ) and 3 are tetranuclear $(4 \mathrm{Fe})$. Complex I can be resolved into three major components: the $P$ fraction, the IP fragment, and the FP fragment (31). The FP fragment, which is water soluble, contains three polypeptides, the FMN cofactor, and six iron atoms, and is reactive with ferricyanide. Since the NADH-ferricyanide reductase activity of the mitochondria and SMPs were identical in the patient and control, it seems likely a portion of the FP fragment of complex I was normal. However, our data give no information about the 
presence of the polypeptide chains of complex I that are presumably involved in the action of the iron-sulfur clusters or about their interaction with the FP fragment. It seems improbable that a congenital defect would involve simultaneous defects in all of these numerous polypeptides; it is more likely that one of the polypeptides is defective and does not permit the normal assembly of the many components of complex I into a functional system. The precedent for this occurs in yeast mitochondria, where cytochrome b deficiency appears to prevent the normal assembly of complex III (32). Alternatively, the enzyme(s) responsible for inserting the iron-sulfur centers into complex I might be absent or altered. However, the capacity of the patient to synthesize other iron-sulfur clusters is apparently normal, since the EPR signals of the outer and the other known inner membrane iron-sulfur clusters are normal. Further identification of the defective entities in complex I will require the use of specific antibodies to the multiple polypeptide subunits of complex I; such antibodies have been described (33). Immunological approaches to the identification of the defective polypeptides, if any, are planned, provided there is enough species cross-reactivity.

The eventual death of the patient was related to the chronic metabolic acidosis, to the progressive accumulations of lipid and glycogen, and to a deficiency in ATP resynthesis. Myofibrils in the heart and skeletal muscle were distorted by the abnormal deposits of lipid, which produced a storage cardiomyopathy. Although the electron microscopic histologic changes are quite striking, especially the concentric whorls of inner and outer mitochondrial membranes, these are not pathognomonic. It is possible that the proliferation of the inner mitochondrial membrane might be a compensatory mechanism for the reduced activity of complex I. However, several lines of evidence argue against this. First, these changes were only seen in skeletal muscle and heart but not in liver, where there was also a pronounced decrease in complex I activity. Furthermore, similar histological changes have been described in both mitochondrial myopathies (14) and ischemic skeletal muscle (34) and may be secondary alterations induced by metabolic changes within the affected tissues. The generalized nature of the disease in the tissues studied at autopsy suggested that mitochondria in other tissues such as brain and nerve may have been affected as well, as indicated by the progressive neurological deterioration of the patient.

Treatment focussed on attempts to control the lactic acidosis. Thiamine, biotin, carnitine, and a ketogenic diet were unsuccessful, as they did not address the basic defect. Dichloroacetate or methylene blue might have reduced the lactic acidosis but would have had no effect on the electron transport defect. Theoretically, treatment would consist of any approach that would result in reoxidation of reduced pyridine nucleotides by the respiratory chain, thus allowing continued oxidation of intermediates of the tricarboxylate cycle and, therefore, a normal capacity to oxidize glucose and fatty acids to $\mathrm{CO}_{2}$ and $\mathrm{H}_{2} \mathrm{O}$, as well as at least some oxidative phosphorylation. Unfortunately, we know of no such measures that would selectively reoxidize reduced pyridine nucleotides of the mitochondria in vivo via any portion of the respiratory chain. That this child lived $4 \mathrm{mo}$ is probably a consequence of a partial rather than complete deficiency in complex $I$ in some organs, as well as an enhanced rate of glycolysis, which could make up some of the deficit in ATP production by the mitochondria and also account for the hypoglycemia and lactic acidemia.

Our patient has one normal sibling and the parents are normal. The one other family reported to have congenital complex I deficiency (15) had unaffected parents and two normal siblings (one male, one female) as well as two affected siblings (one male, one female) who presented in infancy with lactic acidosis, an increased lactate/pyruvate ratio, respiratory distress, cardiomyopathy, and abnormal mitochondria. However, it is apparently possible for defects in $\mathrm{NAD}^{+}$-linked respiration to become profoundly manifest in adulthood. Two female patients (sisters aged 26 and 23) with myopathies characterized by weakness, marked exercise intolerance, and a fluctuating lactic acidemia were recently described (35); mitochondria from one of the sisters were found to have low $\mathrm{NAD}^{+}$-linked respiration but normal succinate respiration, and the authors postulated that the defect was in the NADHubiquinone oxidoreductase segment of the respiratory chain. The same group has more recently described (36) a 46-yr-old male patient with deficient $\mathrm{NAD}^{+}$-linked respiration and normal succinate respiration. Mitochondria from the skeletal muscle of this patient demonstrated normal NADH-ferricyanide reductase activity and the authors suggested the lesion was in the iron-sulfur proteins of complex I, but insufficient material limited more appropriate measurements. Thus it seems likely that a defect similar to that described in this report can present in infancy or adulthood; this raises some questions about the presumed inherited nature of the disease. The pedigree of these cases would be most consistent with an autosomal recessive mode of inheritance. Thus, the variable severity of the defect between tissues in our patient and the other reported cases may be the result of tissue- and age-dependent regulation of gene expression, such as that produced by various isozymes. Although most mitochondrial proteins are coded by nuclear genes, a number of specific polypeptides that are components of the electron transport system are encoded by mitochondrial genes. Indeed, there is recent, but controversial, evidence that some of the polypeptides in complex I may be of mitochondrial origin (37). Much more work is necessary to resolve these intriguing issues.

Prenatal diagnosis is not now available for this inborn error of metabolism. We attempted to demonstrate the defect in the patient's fibroblasts by use of polarographic determinations of oxygen consumption (unpublished data) but were unable to differentiate between affected and normal fibroblasts. Measurement of lactic acid in amniotic fluid would probably not be helpful in this disorder as blood lactate levels were only mildly elevated during the first two weeks of life and the maternal circulation and metabolism would be expected to 
dispose of most of the lactate. Antibodies against complex I have been developed and, depending upon putative identification of a missing polypeptide component(s) in the isolated mitochondria, might permit prenatal diagnosis by use of amniocytes or chorionic villi.

\section{Acknowledgments}

The authors gratefully acknowledge Dr. Adolfo Alexandre for numerous helpful discussions, and Ms. Peggy Ford and Mrs. Susan Cascio for preparing the manuscript.

This work was supported by a grant from the U. S. Public Health Service, National Cancer Institute (CA25360) to Dr. Lehninger.

\section{References}

1. Howell, R. R., D. M. Ashton, and J. B. Wyngaarden. 1962. Glucose-6-phosphatase deficiency glycogen storage disease. Studies on the interrelationships of carbohydrate, lipid, and purine abnormalities. Pediatrics. 29: 553-565.

2. Igarashi, Y., H. Otomo, K. Narisawa, and A. Tadah. 1979. A new variant of glycogen storage disease type 1: probably due to a defect in the glucose-6-phosphate transport system. J. Inherit. Met. Dis. 2:45-49.

3. Lindblad, B., B. S. Lindblad, P. Olin, B. Svanberg, and R. Zetterstrom. 1968. Methylmalonic acidemia. A disorder associated with acidosis, hyperglycinemia, and hyperlactatemia. Acta Paediatr. Scand. 57:417-424.

4. Scholte, H. R., A. E. Meijer, G. K. Van Wijngaarden, and K. L. Leenders. 1979. Familial carnitine deficiency. A fatal case and subclinical state in a sister. J. Neurol. Sci. 42:87-101.

5. Atkin, B. M., M. F. Utter, and M. B. Weinberg. 1979. Pyruvate carboxylase and phosphoenolpyruvate carboxykinase activity in leukocytes and fibroblasts from a patient with pyruvate carboxylase deficiency. Pediatr. Res. 13:38-43.

6. Howarth, J. C., B. H. Robinson, and T. L. Perry. 1981. Lactic acidosis due to pyruvate carboxylase deficiency. J. Inherit. Met. Dis. 4:57-58.

7. Hommes, F. A., K. Bendien, J. D. Elema, H. J. Bremer, and I. Lombeck. 1976. Two cases of phosphoenolpyruvate carboxykinase deficiency. Acta Pediatr. Scand. 65:233-240.

8. Robinson, B. H., J. Taylor, and W. G. Sherwood. 1980. The genetic heterogeneity of lactic acidosis: occurrence of recognizable inborn errors of metabolism in a pediatric population with lactic acidosis. Pediatr. Res. 14:956-962.

9. Pagliara, A. S., I. E. Karl, J. P. Keating, B. I. Brown, and D. M. Kipnis. 1972. Hepatic fructose-1,6-diphosphatase deficiency. A cause of lactic acidosis and hypoglycemia in infancy. J. Clin. Invest. 51:21152123.

10. Robinson, B. H., and W. G. Sherwood. 1975. Pyruvate dehydrogenase phosphatase deficiency: a cause of congenital chronic lactic acidosis in infancy. Pediatr. Res. 9:935-939.

11. Robinson, B. H., J. Taylor, and W. G. Sherwood. 1977 Deficiency of dihydrolipoyl dehydrogenase (a component of the pyruvate and $\alpha$-ketoglutarate dehydrogenase complexes): a cause of congenital chronic lactic acidosis in infancy. Pediatr. Res. 11:1198-1202.

12. Sheu, K.-F. R., C.-W. C. Hu, and M. F. Utter. 1981. Pyruvate dehydrogenase complex activity in normal and deficient fibroblasts. $J$. Clin. Invest. 67:1463-1471.

13. Robinson, B. H., J. Taylor, B. Francois, A. L. Beaudet, and D. F. Peterson. 1983. Lacticacidosis, neurological deterioration and compromised cellular pyruvate oxidation due to a defect in the reoxidation of cytoplasmically generated NADH. Eur. J. Pediatr. 140:98-101.

14. Carafoli, E., and I. Roman. 1980. Mitochondria and disease. In Molecular Aspects of Medicine. H. Baum and J. Gergely, editors. Pergamon Press, Inc., Elmsford, New York. 3:295-429.

15. Kerr, D. S., W. K. Parland, D. T. Wyatt, S. Miller-Paulson, B. Dahms, and C. L. Hoppel. 1980. NADH dehydrogenase deficiency with lactic acidosis, fatty infiltration of viscera, and abnormal mitochondria. Pediatr. Res. 14:576 A. (Abstr.)

16. Pedersen, P. L., J. W. Greenawalt, B. Reynafarje, J. Hullihen, G. L. Decker, J. W. Soper, and E. Bustamante. 1978. Preparation and characterization of mitochondria and submitochondrial particles of rat liver and liver-derived tissues. Methods. Cell. Biol. 20:411-481.

17. Vercesi, A., B. Reynafarje, and A. L. Lehninger. 1978. Stoichiometry of $\mathrm{H}^{+}$ejection and $\mathrm{Ca}^{2+}$ uptake coupled to electron transport in rat heart mitochondria. J. Biol. Chem. 253:6379-6385.

18. Bergmeyer, H. U., editor. 1974. Methods of Enzymatic Analysis. Academic Press, Inc., New York. Second ed. 876-880.

19. Sottocasa, G. L., B. Kuylenstierna, L. Ernster, and A. Bergstrand. 1967. An electron-transport system associated with the outer membrane of liver mitochondria. J. Cell Biol. 32:415-438.

20. Thayer, W. S., and E. Rubin. 1979. Effects of chronic ethanol intoxication on oxidative phosphorylation in rat liver submitochondrial particles. J. Biol. Chem. 254:7717-7723.

21. Ohnishi, T. 1975. Thermodynamic and EPR characterization of iron-sulphur centers in the NADH-ubiquinone segment of the mitochondrial respiratory chain in pigeon heart. Biochim. Biophys. Acta. 387:475-490.

22. Peterson, G. 1977. A simplification of the protein assay method of Lowry, et al., which is more generally applicable. Anal. Biochem. 83:346-351.

23. Siegel, L. M. 1978. Quantitative determination of non-covalently bound flavins: types and methods of analysis. Methods Enzymol. 53:419-429.

24. LaNoue, K. F., and A. C. Schoolwerth. 1979. Metabolite transport in mitochondria. Ann. Rev. Biochem. 48:871-892.

25. Singer, T. P. 1974. Determination of the activity of succinate, NADH, choline, and $\alpha$-glycerophosphate dehydrogenases. Methods Biochem. Anal. 22:151-168.

26. Hatefi, Y. 1978. Preparation and properties of the enzymes and enzyme complexes of the mitochondrial oxidative phosphorylation system. Methods Enzymol. 53:3-54.

27. Ohnishi, T., T. Asakura, T. Yonetani, and B. Chance. 1971. Electron paramagnetic resonance studies at temperatures below $77^{\circ} \mathrm{K}$ on iron-sulphur proteins of yeast. J. Biol. Chem. 246:5960-5964.

28. Albracht, S. P. J., and E. C. Slater. 1971. EPR studies at $20^{\circ} \mathrm{K}$ on the mitochondrial respiratory chain. Biochim. Biophys. Acta. 245:503-507. 
29. Ohnishi, T., J. C. Salerno. 1982. Iron-sulfur clusters in the mitochondrial electron-transport chain. In Iron-Sulfur Proteins. T. G. Spiro, editor. John Wiley and Sons, Inc., New York. 4:285-327.

30. Heron, C., S. Smith, and C. I. Ragan. 1979. An analysis of the polypeptide composition of bovine heart mitochondrial NADH-ubiquinone oxidoreductase by two-dimensional polyacrylamide gel electrophoresis. Biochem. J. 181:435-443.

31. Ragan, C. I., Y. M. Galante, and Y. Hatefi. 1982. Purification of three iron-sulfur proteins from the iron-protein fragment of mitochondrial NADH-ubiquinone oxidoreductase. Biochemistry 21:25182524.

32. Capeillere-Blandin, C., and T. Ohnishi. 1982. Investigation of the iron-sulfur clusters in some mitochondrial mutants of Saccharomyces cerevisiae. Eur. J. Biochem. 122:403-413.

33. Smith, S., I. R. Cottingham, and C. I. Ragan. 1980. Immunological assays of the NADH dehydrogenase content of bovine heart mitochondria and submitochondrial particles. FEBS (Fed. Eur. Biochem. Soc.) Lett. 110:279-282.

34. Heffner, R. R., and S. A. Barron. 1978. The early effects of ischemia upon skeletal muscle mitochondria. J. Neurol. Sci. 38:295315.

35. Morgan-Hughes, J. A., P. Darveniza, D. N. Landon, J. M. Zand, and J. B. Clark. 1979. A mitochondrial myopathy with a deficiency of respiratory chain NADH-CoQ reductase activity. $J$. Neurol. Sci. 43:27-46.

36. Morgan-Hughes, J. A., D. J. Hayes, J. B. Clark, D. N. Landon, M. Swash, R. J. Stark, and P. Rudge. 1982. Mitochondrial encephalopathies. Biochemical studies in two cases revealing defects in the respiratory chain. Brain. 105:553-582.

37. Whitfield, C. D., and R. M. Malczewski. 1983. Decreased levels of mitochondrially synthesized proteins in a Chinese hamster mutant defective in complex I and cytochrome c oxidase. Fed. Proc. 42:1087. 